DOI: $10.20472 / B M .2016 .4 .1 .001$

\title{
ADOPTION OF ELECTRONIC COMMERCE IN THAI TRAVEL SMALL AND MEDIUM ENTERPRISES
}

\section{NARUEMON CHOOCHINPRAKARN}

\begin{abstract}
:
This paper is aim to investigate factors affecting the adoption of e-commerce based on technological, organizational, and environmental (TOE) framework and the extended Model of Internet Commerce Adoption (eMICA). An online survey was employed to collect data from Thai travel small and medium enterprises (SMEs) that have company websites are registered with the Thai Department of Business Development and are a member of the Tourism Authority of Thailand. Data from 125 usable cases was analyzed using multiple regression. Results revealed that (1) only competition intensity positively affected the first (promotion) stage of EC adoption, (2) relative advantage and organizational readiness were found to be the determinants of EC adoption in the second stage of the provision of information and services, and (3) only organizational readiness was found to influence EC adoption in the third (processing) stage. Implications for practice and research are discussed.
\end{abstract}

\section{Keywords:}

E-Commerce Adoption, TOE framework, eMICA model, Travel and tourism industry, small and medium enterprises, SMEs, Thailand

JEL Classification: C36, L81

\section{Authors:}

NARUEMON CHOOCHINPRAKARN, Burapha University , Thailand, Email: naruemon@buu.ac.th

\section{Citation:}

NARUEMON CHOOCHINPRAKARN (2016). ADOPTION OF ELECTRONIC COMMERCE IN THAI TRAVEL SMALL AND MEDIUM ENTERPRISES. International Journal of Business and Management, Vol. IV(1), pp. 1-23., 10.20472/BM.2016.4.1.001 


\section{Introduction}

The tourism industry plays a significant role in income generated in Thailand. In 2015, the revenue from tourism will increase from 1.81 trillion Baht in 2014 to 2.19 trillion Baht. The Tourism Authority of Thailand believes tourism revenue will reach 2.3 trillion Baht in 2016 (Chinmaneevong, 2015). Tourism industry is one of the sectors that can gain the benefits by adopting the Internet and the Web. Tourism businesses can sell and buy products and services through an electronic network known as electronic commerce or e-commerce (EC) (Turban et al., 2008). In addition, EC can be used as a marketing tool to promote company products and/or services, provide information and services to customers, as well as process online sales and payment (Burgess et al., 2001). In 2013 survey of EC Status in Thailand found that EC businesses using EC were mostly travel, hotel and resort (24.0\%) and were small (66.8\%) and medium enterprises (26.6\%) (NSO, 2014). The growth of EC businesses has increased gradually in Thailand. The survey of the National Statistical Office (NSO) in 2012 2014 found that the value of business-to-business EC sales in Thailand increased from 217,458 million Baht in 2010 to 282,946 million Baht in 2012, while business-toconsumer EC sales increased from 67,783 million Baht in 2010 to 121,392 million Baht in 2012. Moreover, EC trend in Thailand was expected to grow by $20-30$ per cent in 2015 (Thongtep, 2014).

Despite the growing number of EC businesses in Thailand, small and medium enterprises (SMEs) are not utilizing EC to its full potential. The majority of SMEs in the trade sector $(68.8 \%)$, mostly in Bangkok and its vicinity, used the Internet for advertising their stores and products. There was a small number of SME entrepreneurs used the Internet for online buying and selling through the Internet (OSMEP, 2012). The limited use of EC by SMEs may due to several factors. Factors influencing EC adoption have been examined extensively in the literature (Chen and McQueen, 2008; Eze, 2008; Ghobakhloo et al., 2011; Ghobakhloo and Tang, 2013; Li and Xie, 2012; Lin and Lin, 2008; Lip-Sam and Hock-Eam, 2011; Ramdani et al., 2013; Zhu et al., 2006). However, limited prior studies have focused on the factors that influence various stages of EC adoption and in Thailand (Jariangprasert et al., 2009; Lertwongsatien and Wongpinunwatana, 2003). This research, therefore, proposes a stage model for EC adoption and factors affecting each stage of EC adoption among Thai Travel SMEs. Thus, the purpose of this research is to answer the following questions (1) What are the factors affecting EC adoption among Thai Travel SMEs?; And (2) 'Are there any differences in each stage of EC adoption?'

The focus of this research was only on tourism businesses, including travel agencies and tour operators, because the Internet offers tourism businesses the potential to make information and booking facilities available to large numbers of tourists at relatively low cost and it also provides a tool for fast communication between tourism suppliers, intermediaries, as well as end-consumers (Wang and Cheung, 2004). 
The definition of SMEs in this research was categorized by using number of employees in the service sector. That is, a small enterprise refers to an enterprise with employees of up to 50 while a medium enterprise refers to an enterprise with between 51 and 200 employees (Bank of Thailand, 2011).

\section{The Extended Model of Internet Commerce Adoption}

In review of the innovation adoption literature, EC adoption can be considered as a series of adoption processes that can be adopted at multiple levels in business processes, e.g. offer information (promotion stage), interaction (provision of information and services), or transactions (processing) (Brand and Huizingh, 2008; Burgess and Cooper, 2000; Zhu et al. 2006). In this research, stages of EC website development followed the theory of the extended Model of Internet Commerce Adoption (eMICA) model developed by Burgess and Cooper (2000). This model is used to evaluate the level of commercial website development. The eMICA model consists of three stages, incorporating three levels of business process - Web-based promotion, provision of information and services, and transaction processing. The eMICA is similar to those that consider EC as a multi-level innovation, with websites that offer information, interaction, or transactions (Dholakia and Kshetri, 2004; Levy and Powell, 2003; Teo and Pian, 2004).

EC may first be used to present the company and its offerings, then the company may add some interactive features by which potential customers get access to information and services tailored to their needs, next the company may include a transaction function for standard products or services, and finally the site may be fully integrated with internal systems (Teo and Pian, 2004). The model allows for a company to enter at any stage. In order to accommodate the wide range of e-commerce development evidenced in industries such as tourism. eMICA incorporates a number of additional layers of complexity, ranging from simple to highly sophisticated, within the identified main stages of the model. The stages and characteristics of the eMICA model (Doolin et al., 2002; Larson and Ankomah, 2004) are summarized in Table 1. However, the adoption of EC will vary with the influence of different factors which will be discussed next. 
Table 1 Stages and Layers of the eMICA Model

$$
\text { eMICA }
$$

Examples of functionality

Stage 1-Promotion (Inception Phase)

Layer 1- basic information

Layer 2- rich information

Sites consist of a simple home page providing basic information such as company name, physical address and other contact information details (phone and fax numbers) and area of business.

Sites contain the information listed in Layer 1 sites plus other extensive information about the company in the form of annual reports, e-mail contact, and detailed information on the company's products/service offerings.

Stage 2-Provision of information and services

Layer 1- low interactivity

Layer 2- medium interactivity

Layer 3- high interactivity
Sites involve lower levels of interactivity and include a basic product catalogues, hyperlink to further information, and online inquiry.

Sites involve medium interactivity characterized by higher-level product catalogues, customer support (e.g., FAQs, site maps), and industry-specific value-added features.

Sites involve higher interactivity and include features such as chat rooms, discussion forums, multimedia, newsletters or updates by email. Other characteristics at these sites include a travel planner, passport/visa requirements, safety information, online tourism magazines, currency converters and language options.

Stage 3-Processing In this phase, the web site has reached maturity and become a "fully-fledged" site. At this stage, the sites are more transaction-based and are characterized by secure on-line transactions, order status and tracking, interaction with corporate servers.

Source: Doolin et al. (2002); Larson and Ankomah (2004)

\section{Technological-Organizational-Environmental Framework}

Factors affecting EC adoption in this study follow the technological-organizationalenvironmental (TOE) framework developed by Tornatzky and Fleischer (1990) since this framework has been widely used to examine the factors that influence the propensity to adopt and use innovation (Ghobakhloo et al., 2011; Ghobakhloo and Tang, 2013; Li and Xie, 2012; Lin and Lin, 2008; Lip-Sam and Hock-Eam, 2011; Ramdani et al., 2013). The Tornatzky and Fleischer' (1990) TOE framework is argued to be an integrative framework that provides a holistic and guiding theoretical basis since research in the adoption/diffusion of ICT typically evaluates various 
technological, organizational, and environmental factors that facilitate or inhibit adoption/diffusion (Ramdani et al., 2013). The TOE framework is consistent with Rogers' (1995) theory of innovation diffusion in which he identified individual characteristics, and both the internal and external characteristics of the organization (Zhu et al., 2006), as antecedents of innovation adoption. The TOE framework has been claimed to be a generic theory of technology adoption/diffusion (Zhu et al., 2003) that can be used to study EC adoption by SMEs. In the next section factors influencing each stage of EC adoption and proposed hypothesis will be discussed.

\subsection{Technological context}

Technological context describes both the internal and external technologies relevant to the firm. This includes existing technologies inside the firm, as well as the pool of available technologies in the market. As revealed from reviewing the literature (AlQirim, 2007; Lin, 2006; Ramdani et al., 2013), two factors that seem to be the primary focus in this context in SMEs are relative advantage and compatibility. Thus, they were employed as factors that influence the decision of innovation adoption in the technological context and will be discussed next.

\subsubsection{Relative advantage}

Relative advantage is defined as "the degree to which an innovation is perceived as being better than the idea it supersedes" (Rogers, 2003, p. 229). Relative advantage can be viewed as perceived benefits (lacovou et al., 1995) and potential value (Brand and Huizingh, 2008). Several studies found evidence of a positive influence of relative advantage of EC on EC adoption by SMEs (e.g. Brand and Huizingh, 2008; Ghobakhloo and Tang, 2013; Wang and Ahmed, 2009). Further, relative advantage was found to be a significant factor in determining enterprise applications adoption (Ramdani et al., 2013). The benefits from EC for companies are numerous such as, expanding markets, reducing costs, increasing operational efficiency, and increasing relationships with customers (Baltzan and Phillips, 2009). In a highly competitive environment, these benefits provide significant motivation for EC adoption. Therefore, it is hypothesized that:

H1: Relative advantage is positively related to (a) promotion, (b) provision, and (c) processing stages of EC adoption.

\subsubsection{Compatibility}

Compatibility can be defined as compatibility between EC and firm's culture, values, and exiting business processes (Grandon and Pearson, 2004). Prior studies found that EC adoption is significantly affected by EC compatibility. For example, Ghobakhloo and Tang (2013) found a positive relationship between EC compatibility and EC application adoption by Iranian small businesses. Further, Zhu et al. (2006) found that technology integration is positively related to e-business initiation, adoption, and routinization as well as a key determinant of e-business assimilation, especially in 
developed countries. Similarly, Hong and Zhu (2006) found that technology integration was a significant EC adoption predictor. Thus, it is hypothesized that:

H2: Compatible EC with the current systems is positively related to (a) promotion, (b) provision, and (c) processing stages of EC adoption.

\subsection{Organizational context}

Organizational context is typically referred to as descriptive measures about the organization such as size and scope; the centralization, formalization, and complexity of its managerial structure; the quality of its human resources; and the amount of slack resources available internally. Due to characteristics of SMEs that are small scale of operations and insufficient resources, organizational readiness is used to examine its relationship to innovation adoption in several studies (Ramdani et al., 2013; Wang and Ahmed, 2009). In addition, the roles of top managers were frequently seen as a key determining factor that influences innovation adoption in SMEs (AI-Qirim, 2007; Ghobakhloo and Tang, 2013; Ramdani et al., 2013). In SMEs, the organizational structure is less complex and simpler to manage. Top managers in SMEs usually refer to the CEO, who makes most of the critical decision (Mintzberg, 1979). This study, therefore, examines organizational readiness and top management (CEO) support as the determinants in the organizational context of EC adoption.

\subsubsection{Organizational readiness}

Organizational readiness was one of the most frequently examined determinants in the studies of innovation adoption. lacovou et al. (1995) consider organizational readiness in two dimensions, financial and technological readiness. Financial readiness refers to whether an organization has sufficient financial resources to invest on new technologies, whilst technological readiness is concerned with the level of technology sophistication. In the small business realm, organizational readiness plays a significant role in new technology adoption (Wang and Ahmed, 2009). The study of Ramdani et al. (2013) confirms the significant role of organizational readiness in determining enterprise applications adoption by SMEs in the northwest of England. Further, technology readiness (infrastructure, relevant systems, technical skills) was found to be an important factor for successful IS adoption and e-business assimilation (Zhu and Kraemer, 2005; Zhu et al., 2006). Thus, it is hypothesized that:

H3: Organizational readiness is positively related to (a) promotion, (b) provision, and (c) processing stages of EC adoption.

\subsubsection{Top management support}

Top management support can stimulate change by communicating and reinforcing values through an articulated vision for the organization (Thong, 1999). Previous studies on SMEs innovation adoption revealed that top management support/managerial involvement is crucial in adoption of EC (Kenneth et al., 2012), 
enterprise applications adoption (Ramdani et al., 2013), and Intranet adoption (AlQirim, 2007). In addition, managerial enthusiasm towards EC, a positive attitude towards EC, and being closely involved in EC implementation leads to a higher level of EC adoption (Chen and McQueen, 2008). It can be concluded that top management support was perceived as a necessary determinant to the adoption of EC. Thus, it is hypothesized that:

H4: Top management support is positively related to (a) promotion, (b) provision, and (c) processing stages of EC adoption.

\subsection{Environmental context}

Environmental context is the arena in which a firm conducts its business - its industry, competitors, access to resources supplied by others, and dealings with government (Ghobakhloo and Tang, 2011). Several studies (AI-Qirim, 2007; Lin, 2006; Ramdani et al., 2013; Zhu et al., 2006) suggest that competition intensity was used as the determinant in the environmental context of EC adoption. Premkumar and Ramamurthy (1995) argue that it is a strategic necessity to adopt the new technologies to compete in the marketplace. Thus, competition intensity is considered as an influence factor of EC adoption in the environmental context.

\subsubsection{Competition Intensity}

Competition intensity refers to the degree that the company is affected by competitors in the market (Zhu et al., 2004). Most empirical studies indicated that higher competition intensity is associated with higher adoption rates. For example, the study of Ramdani et al. (2013) found support for the influence of competition pressure on enterprise applications adoption by SMEs in the northwest of England. Moreover, Lin and Lin (2008) examined factors influencing e-business diffusion in Taiwan. Results showed that the emergence of competitive pressure was a key determinant of integration and diffusion of e-business. Similarly, Zhu et al. (2006) explored innovation assimilation in e-business in different countries and found that competition positively affected initiation and adoption of e-business. Additionally, Lertwongsatein and Wongpinunwatana (2003) investigated EC adoption for SMEs in Thailand. Results showed that EC adopters' were more likely to operate in a highly competitive environment. Thus, it is hypothesized that:

H5: Intensity of competition is positively related to (a) promotion, (b) provision, and (c) processing stages of EC adoption.

The proposed hypothetical links guiding this study are shown in Figure 1. 
Figure 1 The Conceptual Model of EC Adoption in Thai Travel SMEs

Technological context

\section{Three-stage of e-commerce adoption}

\begin{tabular}{|c|c|}
\hline Relative Advantage & $\mathrm{H} 1$ \\
\hline Compatibility & $\mathrm{H} 2$ \\
\hline
\end{tabular}

\section{Organizational context}

\begin{tabular}{|c|c|}
\hline Organizational Readiness & $\mathrm{H} 3$ \\
\hline Top Management Support & $\mathrm{H} 4$ \\
\hline
\end{tabular}

Stage 1-promotion

Environmental context

Competition Intensity

\section{Methodology}

To test the hypotheses proposed in this research, an online survey was employed in collecting data. The questionnaire was translated into Thai by an expert in EnglishThai translation in the University. The questionnaire was tested for content validity with three lecturers in the University. The population in this study comprises of 405 of travel and tourism companies that were registered with the Thai Department of Business Development and the Tourism Authority of Thailand, have an active website, and were Thai SMEs. Due to this being a small population, all were included in this study. The questionnaire was sent to managers or CEOs of travel and tourism companies included in this study via email including link to the survey website during 1 September - 30 November 2012. A follow up email was sent to non-responsive participants during 15 August -31 August 2013. A total of 131 respondents were received and 125 were usable for data analysis, yielding a response rate of 30 per cent. This number of sample size would be reasonable for the multiple regression technique as suggested by Green (1991). Data was analyzed using descriptive statistics, F-tests, and regression analysis.

\subsection{Measurement}

EC adoption in each stage was assessed with the use of 33 website functionalities adopted from Larson and Ankomah (2004), following the eMICA model. Participants were asked to select the EC functionality items that their organization adopted for their businesses. They were able to choose as many items as applied. The operational 
definitions and criteria to classify the stage of EC adoption are shown in Table 2. The three stages of EC adoption were not examined for the reliability and validity tests as they were not multidimensional variables. Then, the items were aggregated to form each stage of dependent variables.

Table 2 Constructs of the E-Commerce Adoption (eMICA)

\begin{tabular}{|c|c|c|c|}
\hline Stage & Operationalization & $\begin{array}{c}\text { Item(s) } \\
\text { Provided }\end{array}$ & $\begin{array}{l}\text { Minimum Item(s) to } \\
\text { Achieve These Stage }\end{array}$ \\
\hline \multicolumn{4}{|c|}{ Stage 1- Promotion Stage of EC Adoption } \\
\hline & Layer 1- basic information & 1 & 1 \\
\hline & Layer 2- rich information & 2 & 1 \\
\hline \multicolumn{4}{|c|}{ Stage 2- Provision Stage of EC Adoption } \\
\hline & Layer 1 - low interactivity & 3 & 2 \\
\hline & Layer 2- medium interactivity & 7 & 5 \\
\hline & Layer 3- high interactivity & 14 & 7 \\
\hline \multicolumn{2}{|c|}{ Stage 3-Processing Stage of EC Adoption } & 3 & 2 \\
\hline
\end{tabular}

Source: Adapted from Larson and Ankomah (2004)

The five technological, organizational, and environmental factors were assessed with 25 items, adopted from Al-Qirim (2005); Eze (2008); Zhu et al. (2006); Grandon and Pearson (2004); and Lin (2006). These items were appeared in a random manner. Respondents were asked to rate each item using a seven-point Likert scale where (1) corresponds to 'Strongly Disagree' and (7) corresponds to'Strongly Agree'.

\subsection{Construct reliability}

Construct reliability of the five TOE factors was assessed using Cronbach's alpha coefficient (Cronbach 1951). The results as reported in Table 3 revealed that there were three variables with coefficient alphas higher than the acceptable cut-off point of 0.70 (Peterson, 1994), ranging from 0.811 to 0.878 . For these three variables, relative advantage, compatibility, and top management support, internal consistency appeared to be high. However, another two variables, competition intensity and organizational readiness, had reliability coefficients of 0.644 , and 0.625 respectively, which were lower than the acceptable cut-off point of 0.70 . However, Robinson et al. (1991) suggest that alpha may decrease to 0.60 in exploratory research. Thus, these two variables were included in this study but were treated with caution.

\subsection{Construct validity}

Construct validity of the five TOE factors was performed using exploratory factor analysis (EFA) with principal components analysis and varimax rotation. The results indicated that factor loadings were all positive and above the cut-off value of 0.4 (Gefen and Straub, 2000), which represented acceptable construct validity as reported in 
Table 3. The average values of these five independent variables were then used for hypothesis testing.

Table 3 Results of Cronbach's Reliability Coefficients and Factor Loadings for the Constructs

$\begin{array}{lll}\text { Constructs } & \text { Cronbach's Alpha Range of Factor Loading No. of Items }\end{array}$

$\begin{array}{llll}\text { (1) Relative advantage } & 0.878 & 0.559-0.736 & 9 \\ \text { (2) Compatibility } & 0.855 & 0.489-0.822 & 7 \\ \text { (3) Organizational readiness } & 0.625 & 0.736-0.776 & 2 \\ \text { (4) Top management support } & 0.811 & 0.622-0.849 & 4 \\ \text { (5) Competition intensity } & 0.644 & 0.557-0.692 & 3\end{array}$

Prior to conducting multiple regression analysis, the three major assumptions of a multiple regression, including normality, linearity, and homogeneity of variance (Hair et al. (2006) were examined and found no major violations.

\section{$5 \quad$ Findings}

\subsection{Demographic Profiles of Respondents}

Of the 125 respondents, the majority (about 39\%) employed between one and five employees; approximately $86 \%$ were located in Bangkok; and 30\% had implemented EC for more than eight years. Almost $45 \%$ of respondents were at chief executive officer level. Table 4 summarizes the demographic details of the respondents.

Table 4 Demographic Characteristics of the Respondents $(n=125)$

\begin{tabular}{llcc}
\hline \multirow{2}{*}{ Category } & & Frequency & Per cent (\%) \\
\hline \multirow{2}{*}{ Number of Employee } & $1-5$ & 49 & 39.2 \\
& $6-15$ & 41 & 32.8 \\
& $16-50$ & 26 & 20.8 \\
& $51-100$ & 8 & 6.4 \\
& $101-200$ & 1 & 0.8 \\
Organization Location & & & \\
& Bangkok & 107 & 85.6 \\
& Eastern region & 2 & 1.6 \\
& Southern region & 12 & 9.6 \\
& Northern region & 2 & 1.6 \\
& Central region & 2 & 1.6 \\
& & & \\
Years of implementing EC & Less than a year & 2 & 17.6 \\
& 1-2 years & 22 & 27.2 \\
& 3-5 years & 37 & 18.4
\end{tabular}


Current Position

CEO

General Manager

\subsection{EC Adoption}

Results revealed that more than half $(54 \%)$ of Thai Travel SMEs websites in this research were developed to stage 2 of EC adoption (eMICA); $24 \%$ of them were in Stage 2 Level 3, around 22\% were in Stage 2 Level 1 and around 9\% were in Stage 2 Level 2. For Stage 1 and Stage 3 of EC adoption, they were almost equal at around $23 \%$ and $22 \%$ respectively. Results of EC adoption in each stage are summarized in Table 5.

Table 5 Stage of E-Commerce Adoption (eMICA) by Thai Travel SMEs

\begin{tabular}{lll}
\hline Stage & Frequency & Per cent $(\%)$ \\
\hline
\end{tabular}

\begin{tabular}{lrr} 
Stage 1- Promotion & & \\
Level 1 & 2 & 1.6 \\
Level2 & 27 & 21.6 \\
\hline Sub-Total & 29 & 23.2 \\
\hline
\end{tabular}

Stage 2- Provision

\begin{tabular}{ccc} 
Level 1 & 27 & 21.6 \\
Level 2 & 11 & 8.8 \\
Level 3 & 30 & 240 \\
\hline Sub-Total & 68 & 54.4 \\
\hline
\end{tabular}

Stage 3-Processing 28 22.4 Grand Total 125 1000

\subsection{Hypotheses Tests}

Table 6 shows the results of the multiple regression analysis of the three stages and five TOE factors only for the factors that appeared as significant in the tests. In addition, the multicollinearity problem for the different independent variables was examined using VIF. The highest VIF values of the different independent variables were all acceptable, being less than five (Hossain Academy, 2012). Thus, there is no collinearity associated with the independent variables. Likewise, auto correlation 
problems were tested using Durbin-Watson. As shown in Table 6, the Durbin-Watson value of 2.065 for determinants of stage 1 of EC adoption, 2.218 for determinants of stage 2 of EC adoption, and 1.944 for determinants of stage 3 of EC adoption are between 1.5 and 2.5, which demonstrates that there are no auto correlation problems in the data used in this study (Hair et al., 2006). The model tested and the estimated coefficients on the adoption in each stage are also shown in Table 6, only significant variables are shown. Details in each stage are discussed below:

Table 6 Results of the Regression Model in Each Stage

\begin{tabular}{|c|c|c|c|c|c|c|c|c|}
\hline Variables & $F$ & Sig. & $\begin{array}{c}\text { Adjusted } \\
R^{2}\end{array}$ & $\begin{array}{l}\text { Durbin- } \\
\text { Watson }\end{array}$ & Beta & Sig & \multicolumn{2}{|c|}{$\begin{array}{c}\text {.Collinearity } \\
\text { Statistics } \\
\text { Tolerance VIF }\end{array}$} \\
\hline 1. Promotion Stage & $\begin{array}{c}8.423 \\
(1,123)\end{array}$ & 0.004 & 0.056 & 2.065 & & & & \\
\hline a. Competition intensity & & & & & $0.253^{\star *}$ & 0.004 & 1.000 & 1.000 \\
\hline 2. Provision Stage & $\begin{array}{c}9.411 \\
(2,122)\end{array}$ & 0.000 & 0.119 & 2.218 & & & & \\
\hline a. Relative advantage & & & & & $0.229^{*}$ & 0.013 & 0.850 & 1.777 \\
\hline b. Organizational readiness & & & & & $0.209^{*}$ & 0.024 & 0.850 & 1.777 \\
\hline 3. Processing Stage & $\begin{array}{c}16.832 \\
(1,123)\end{array}$ & 0.000 & 0.113 & 1.944 & & & & \\
\hline a. Organizational readiness & & & & & $0.347^{\star *}$ & 0.000 & 1.000 & 1.000 \\
\hline
\end{tabular}

** Significant at the 0.01 level

* Significant at the 0.05 level

\subsubsection{Promotion Stage of EC Adoption}

The predictor of the promotion stage of EC adoption was competition intensity only, $F(1,123)=8.423, p=0.004$. The adjusted $R^{2}$ value was 0.056 , which meant that $5.6 \%$ of the variance in the promotion stage of $\mathrm{EC}$ adoption was explained by competition intensity. The effect size of this model was quite small (Leech et al. 2005). The results also indicated that competition intensity had statistical significance at the 0.01 level ( $p$ $=0.004$ ) on predicting the promotion stage of EC adoption with a positive influence $(b e t a=0.253)$. Other factors did not significantly contribute to the model for predicting the promotion stage of EC adoption. Therefore, only Hypothesis 5(a) was supported.

\subsubsection{Provision Stage of EC Adoption}

The results of the provision stage of EC adoption indicated two factors, relative advantage and organizational readiness, significantly predicted the provision stage of EC adoption, $F(2,122)=9.411, p<0.001$. The adjusted $R^{2}$ value was 0.119 , which 
meant that $11.9 \%$ of the variance in the provision stage of EC adoption was explained by relative advantage and organizational readiness. The effect size of this model was also quite small (Leech et al. 2005). The results indicated that relative advantage was statistically significant in predicting the provision stage of EC adoption at the 0.05 level $(p=0.013)$ with a positive influence (beta $=0.229)$. The results also indicated that organizational readiness was statistically significant in predicting the provision stage of EC adoption at the 0.05 level ( $p=0.024$ ) with a positive influence (beta $=0.209$ ). Other factors did not significantly contribute to the model for predicting the provision stage of EC adoption. Therefore, Hypothesis 1(b) and Hypothesis 3(b) were supported.

\subsubsection{Processing Stage of EC Adoption}

The results of the processing stage of EC adoption indicated that only organizational readiness significantly predicted stage 3 of $E C$ adoption, $F(1,123)=16.832, p<0.001$. The adjusted $R^{2}$ value was 0.113 , which meant that $11.3 \%$ of the variance in the processing stage of EC adoption was explained by organizational readiness. The effect size of this model was also small (Leech et al. 2005). The results indicated that organizational readiness was statistically significant on predicting the processing stage of EC adoption at the 0.01 level $(p<0.000)$ with a positive influence (beta $=$ $0.347)$. Other factors did not significantly contribute to the model for predicting stage 3 of EC adoption. Therefore, only Hypothesis 3(c) was supported.

Results of hypotheses testing are summarized in Table 7.

Table 7 Summary Results of Multiple Regression Analysis

\begin{tabular}{|c|c|}
\hline Hypothesis & Result \\
\hline $\begin{array}{l}\text { H1: Relative advantage is positively related to (a) } \\
\text { promotion, (b) provision, and (c) processing } \\
\text { stages of EC adoption. }\end{array}$ & The $\mathrm{H} 1(\mathrm{~b})$ is supported. \\
\hline $\begin{array}{l}\text { H2: Compatible EC with the current systems is } \\
\text { positively related to (a) promotion, (b) } \\
\text { provision, and (c) processing stages of EC } \\
\text { adoption. }\end{array}$ & This hypothesis is not supported. \\
\hline $\begin{array}{l}\text { H3: Organizational readiness is positively related to } \\
\text { (a) promotion, (b) provision, and (c) processing } \\
\text { stages of EC adoption. }\end{array}$ & The $\mathrm{H3}(\mathrm{b})$ and $\mathrm{H} 3$ (c) are supported. \\
\hline $\begin{array}{l}\text { H4: Top management support is positively related } \\
\text { to (a) promotion, (b) provision, and (c) } \\
\text { processing stages of EC adoption. }\end{array}$ & This hypothesis is not supported. \\
\hline $\begin{array}{l}\text { H5: Intensity of competition is positively related to } \\
\text { (a) promotion, (b) provision, and (c) processing } \\
\text { stages of EC adoption. }\end{array}$ & The H5(a) is supported. \\
\hline
\end{tabular}




\section{Discussion}

This research found that TOE factors played different roles on EC adoption according to the stage of EC adoption. The adoption of EC by Thai travel SMEs in the promotion stage (Stage 1) was found to depend only on their perceived greater competition environment amongst their competitors. This means that Thai travel SMEs adopted EC because they perceived greater competition amongst their competitors. Thai travel SMEs are more likely to adopt EC for promoting their businesses by using the Internet as a new channel to commercialize their products and maintain a competitive advantage. The result of this study supports previous research that EC adoption in SMEs is significantly and positively affected by competitiveness of the environment (Ghobakhloo et al., 2011; Lin and Lin, 2008; Zhu et al., 2006). Since the travel industry has a high level of competition amongst organizations (NSO, 2013), EC can be used as a strategic tool to respond to competitors (Lertwongsatein and Wongpinunwatana, 2003) in order to remain competitive advantage and survival. By creating a website at this stage, a Thai travel SME can introduce its products, reach new markets, and provide contact points through this new sales channel anytime and anywhere (Laudon and Laudon 2009).

In addition, the results of this research indicated that relative advantage and organization readiness were significant predictor of stage 2 of EC adoption. This means that when Thai travel SMEs perceived greater relative advantage of the Internet and EC technologies they then moved to the provision stage of EC adoption (Stage 2). This suggests that Thai travel SMEs are more likely to adopt EC for provision of information and services to increase sales, enlarge their market share, reduce costs, and develop new business models. The results of this research confirmed prior empirical studies, which found that relative advantage was a significant predictor of EC adoption (Brand and Huizingh, 2008; Lin, 2006; Ghobakhloo and Tang, 2013; Wang and Ahmed, 2009). Ramsey et al. (2003) argue that growing awareness and understanding of the benefits of EC among SMEs can positively influence their desire and interest in adopting EC. In addition, Thai travel SMEs are more likely to move from stage 1 to stage 2 when their organization have sufficient financial and technological resources to support EC operation. The result of this research was in line with Rashid and Al-Qirim (2001) who state that financial, human, and technology resources play a vital role in the adoption of EC.

Lastly, this research found that organizational readiness was also a significant predictor of stage 3 of EC adoption. This means that Thai travel SMEs are more likely to be advanced in the processing stage (Stage 3) in adopting online transactions, e.g. to make secure online payments, order tracking and online sales of souvenirs, etc. when their organization had sufficient financial and technological resources. As mentioned in stage 2, financial, human, and technological resources play a vital role in the adoption of EC. Moreover, Zhu et al. (2006) suggested that in developing countries, technology readiness is the most critical factor for e-business assimilation. 
In addition, in later stages of EC adoption, costs, technological demands, and complexity increase (Rao et al., 2003). Thus, only those organizations with sufficient resources would consider expanding by adopting EC (Wang and Ahmed, 2009).

However, this research failed to reveal the effects of compatibility and top management support. These factors did not appear to play any significant role in EC adoption in this research. This will be discussed next.

Compatibility. Compatibility of EC with the current system was insignificant to EC adoption. This means that Thai travel SMEs did not perceive that the compatibility of EC systems and current buying and selling processes, customers, security, and EC legal issues are important issues in their EC adoption. This finding did not confirm prior empirical studies as presented by Zhu et al. (2006). A plausible explanation could be that EC/IS implementation in the Thai travel SMEs may require significant organizational and structural changes (Levy et al., 2002), change in existing work practices, and/or in culture of organizations (Nguyen, 2009). However, these SMEs face the difficulty in changing the existing systems to match the EC systems (Khan, 2004). Thus, compatibility can be considered as a barrier to adopting EC in Thai travel SMEs

Top management support. Top management support was insignificant to EC adoption in this research. This finding was inconsistent with prior empirical studies which indicates that top management support influence website and EC adoption significantly and positively (Ghobakhloo and Tang, 2013; Ghobakhloo et al., 2011; Ramdani et al., 2013). Although top management perceived the importance of EC adoption, they often do not have sufficient resources to adopt them (Thong and Yap, 1995). In addition, EC was considered as a new technology for organizations and needs technologically skilled employees to operate and maintain those EC systems (Thong and Yap, 1995). Moreover, top management of Thai Travel SMEs may consider that EC implementation is a risky investment in terms of a low return on investment (Vilaseca-Requena et. al., 2007; Chen and McQueen, 2008), coupled with insufficient customer' access to the Internet (Chen and McQueen, 2008), and privacy risks and lack of trust and security (Molla and Licker, 2005; Tan et al., 2009). Thus, top managements of SMEs in developing countries, including Thailand, are generally reluctant to adopt and use EC (Ghobakhloo and Tang, 2013).

\section{Conclusion and implication}

\subsection{Theoretical implications}

The major contribution of this study to the research in EC adoption is that this research might be one of the first studies that has investigated the use of EC by Thai travel SMEs using the eMICA three-stage model and examined factors affecting EC adoption in each stage following the TOE framework. The results of this study provide support 
for the TOE framework by suggesting that competition intensity, perceived relative advantage of EC, and organizational readiness are significant influential factors of EC adoption by Thai travel SMEs more than other, but in different stages. In addition, the significant impact of certain factors on each stage of EC adoption suggests the uniqueness of the adoption phenomenon of EC in Thai travel SMEs on their adoption decision in each stage. From the first stage, promotion stage, the influence factor to adopt EC came from environmental context, competition intensity. In order to survive from external threats in the competitive environment, Thai travel SMEs were forced to adopt $\mathrm{EC}$ in the first stage.

In contrast, the motivation for organizations to proceed to the next stage came from technological (relative advantage) and organizational (organizational readiness) context. When Thai travel SMEs recognized the potential benefits of EC technology over traditional methods as well as had sufficient IT skill employees in the organization; they would proceed to the next stage, stage 2. In addition, organizations have moved to more advanced stages of EC, the processing stage, when their organization had sufficient financial and technological resources. This can be seen that organizational readiness plays a significant role in stage 2 and stage 3.

\subsection{Practical Implications}

The findings provide several implications for managers, government agencies, and EC consultants and vendors in providing guidance on practical applications of EC adoption in Thai travel SMEs and in developing EC adoption models. First, this study suggests that managers need to adjust management practices according to the stage model. Understanding the level of EC adoption will have an important impact on the competitive positioning of Thai travel SMEs depending on the purpose of the adoption. E-commerce may be first used only to provide product and service information of the company. After that, more functionality may be added to the website to interact with customers and provide information and services they need. In the next step, the company may add an online transaction function for products or services. Finally, the site maybe fully integrated with the system by considering influencing factors in each stage. To ensure the use of the Web into the maturity and becoming a fully-fledged site, organizations need to build up organizational readiness. Top managers should put a high priority on investing in EC technology and linking the systems across the organization to support information flow across the value chain (Zhu et al. 2006). In addition, managers need to enhance their employees' knowledge on ICT proficiency and ICT trends (Law et al., 2009) for the efficient use and adoption of innovation by working closely with EC vendors in providing more technical support, training, and peer information (Zhu et al. 2006). Thai travel SMEs can take this information into account in the implementation and use of EC to help improve business performance and managerial decision making (Leung and Law, 2005) to create a competitive advantage in the global market. 
This study also offers implications for government agencies. Firstly, according to UNCTAD (2004), in order to stimulate the use of EC in SMEs in Thailand, government agencies should play an important role in facilitating the use of EC for the tourism industry and in increasing their ability to reap benefits (Kenneth et al., 2012). In Thailand, the government agencies, e.g. Department of Business Development and Department of Industry Promotion, have provided several EC training programs and workshops to support and enhance SMEs competitiveness. However, Thai SMEs might be unaware, or are ignorant, of the support provided by government agencies. Therefore, government agencies and EC consultants should put more effort into promoting the use of EC by raising the awareness of EC advantages on SMEs' businesses (Ghobakhloo and Tang, 2013) and expanding the knowledge of EC by providing continuing EC training programs and workshops as well as providing flexible learning opportunities for owner/managers who are busy in managing daily business and seeking new business opportunities (Xu et al., 2007).

Additionally, government agencies could provide financial support programs (e.g. low interest loans) targeted at SMEs that would like to migrate to EC systems. SMEs in Thailand may be concerned with the tax issues of EC operations. The government, therefore, could accelerate EC diffusion by modifying current tax laws to stimulate EC adoption by SMEs (Lin, 2006). Moreover, one of the main barriers of EC adoption faced by SMEs in Thailand is security of online transactions. Thus, government agencies should focus their supporting activities on lowering perceived risks of EC by improving secure order processing and payment systems by establishing a legal and institutional framework that supports EC and online transactions (Ghobakhloo and Tang, 2013; Kraemer et al., 2006).

Finally, EC vendors could play a significant role in enhancing the widespread adoption of EC among Thai SMEs who have a lack of IT expertise, specialist knowledge, and resources. EC vendors and technology providers are advised to provide EC solutions that add value to owners/managers by offering tailor-made EC solutions to suit the unique needs (Xu et al., 2007) of Thai travel SMEs. In addition, vendors' support and training should be prioritized to SMEs clients (Xu et al., 2007) and enhancing user satisfaction and innovation effectiveness (Ghobakhloo and Tang, 2013; Zhu et al., 2006) in order to strengthen good relationships between each other and increase the rate of EC adoption among Thai travel SMEs.

\subsection{Limitations and future research directions}

There are some limitations of this study. First, the selective choice of independent variables tends to pose certain limitations to the study. Second, the study's sample size of 125 travel and tour SMEs is not a large enough sample to better detect relationships due to low statistical power (Hair et al., 2006). Third, the research was limited to Thai travel SMEs including only travel and tour operators and are from two 
sources, DBD and TAT. This could be a limitation about the generalizability of the results.

The results of this study serve as a preliminary step towards a better understanding of strategic uses of EC in Thai travel SMEs as well as factors affecting EC and adoption. For future research, there are several directions that may be developed from this study. First, in order to generalize the concepts, future research should be extended to incorporate other sectors of the travel industry such as accommodation, so that the unique needs and problems related to the travel industry in adopting EC technology can be appropriately addressed and the findings generated from different sectors can be compared in the context of developing an EC adoption model. Second, future research may replicate this study by including other sources of the population to verify the research findings. Finally, future research should further explore impacts of other factors that were not included in this study, e.g. government support, consultant effectiveness, cost of EC implementation, in order to improve the effect size of the model.

\section{Acknowledgements}

This work was financially supported by the Office of the Higher Education Commission, Thailand. The support is gratefully acknowledged.

\section{References}

AL-QIRIM, N. (2005) An empirical investigation of an e-commerce adoption-capability model in small businesses in New Zealand. Electronic Markets. Vol.15, No. 4, pp. 418-437.

AL-QIRIM, N. (2007) The adoption of eCommerce communications and applications technologies in small business in New Zealand. Electronic Commerce Research and Applications. Vol. 6, pp. 462-473.

BANK of THAILAND. (2011, June 28) Key challenges for SMEs financial access in Thailand. Retrieved from: http://www.adfiap.org/wp-content/uploads/2011/06/Economy-Presentation-Thailand.pdf

BALTZAN, P. and PHILLIPS, A. (2009) Essentials of Business Driven Information Systems. New York : McGraw-Hill Irwin.

BRAND, M.J. and HUIZINGH, E.K.R.E. (2008) Into the drivers of innovation adoption: What is the impact of the current level of adoption?. European Journal of Innovation Management. Vol.11, No.1, pp. 5-24.

BURGESS, L. and COOPER, J. (2000) Extending the viability of MICA (Model of Internet Commerce Adoption) as a metric for explaining the process of business adoption of Internet commerce. Paper presented at the International Conference on Telecommunications and Electronic Commerce, Dallas, November. In: Doolin, B, Burgess, L. and Cooper, J. (2002) Evaluating the use of the Web for tourism marketing: a case study from New Zealand. Tourism Management. Vol. 23, pp. 557-561. 
BURGESS, L., COOPER, J. and ALCOCK, C. (2001) The adoption of the Web as marketing tool by Regional Tourism Associations (RTAs) in Australia. ACIS2001 Proceedings. Retrieved from: http://aisel.aisnet.org/acis2001/9

CHEN, J. and McQUEEN, R.J. (2008) Factors affecting e-commerce stages of growth in small Chinese firms in New Zealand: An analysis of adoption motivators and inhibitors. Journal of Global Information Management. Vol. 16, No. 1, pp. 26-60.

CHINMANEEVONG, C. (2015, October 6) TAT intends to boost domestic tourism. Bangkok Post, Retrieved from: http://www.bangkokpost.com/business/tourism-and-transport/719284/tat- intends-toboost-domestic-tourism

CRONBACH, L.J. (1951) Coefficient alpha and the internal structure of tests. Psychometrika. Vol. 16, pp. 297-335.

DHOLAKIA, R.R. and KSHETRI, N. (2004) Factors impacting the adoption of the Internet among SMEs. Small Business Economics. Vol. 23, No. 4, pp. 311-22.

DOOLIN, B., BURGESS, L. and COOPER, J. (2002) Evaluating the use of the Web for tourism marketing: a case study from New Zealand. Tourism Management. Vol. 23, pp. 557-561.

EZE, U.C. (2008) E-business deployment in Nigerian financial firms: an empirical analysis of key factors. International Journal of E-Business Research. Vol. 4, No. 2, April-June, pp. 2 -4.

GEFEN, D. and STRAUB, D. (2000) The relative importance of perceived ease of use in IS adoption: a study of e-commerce adoption. Journal of the Association for Information Systems. Volume 1, Article 8. Retrieved from: http://www.cis.gsu.edu/dstraub/Courses/MGS\%209940/2007/TimMathieu-Betrice\%20choice.pdf

GHOBAKHLOO, M. and TANG, S.H. (2013) The role of owner/manager in adoption of electronic commerce in small businesses: The case of developing countries. Journal of Small Business and Enterprise Development. Vol.20, No. 4, pp. 754-787.

GHOBAKHLOO, M., ARIAS-ARANDA, D. and BENITEZ-AMADO, J. (2011) Adoption of e-commerce applications in SMEs. Industrial Management \& Data Systems. Vol.111, No. 8, pp. 1238-1269.

GRANDON, E.E. and PEARSON, J.M. (2004) Electronic commerce adoption: an empirical study of small and medium US businesses. Information \& Management. Vol. 42, pp. 197-216.

GREEN, S.B. (1991) How many subjects does it take to do a regression analysis?. Multivariate Behavioral Research. Vol. 26, pp. 499-510.

HAIR, J.F., BLACK, W.C., BABIN, B.J., ANDERSON, R.E., and Tatham, R.L. (2006). Multivariate data analysis, 6th ed. Upper Saddle River, New Jersey: Prentice Hall.

HONG, W. and ZHU, K. (2006) Migrating to internet-based eCommerce: factors affecting eCommerce adoption and migration at the firm level. Information \& Management. Vol. 43, No. 2, pp. 204-221.

HOSSAIN ACADEMY. (2012) Multicollinearity and Regression Model One. Part 1 of 3. Retrieved from: http://www.chsbs.cmich.edu/fattah/courses/empirical/ multicollinearity.html 
IACOVOU, C.L., BENBASAT, I. and DEXTER, A.S. (1995) Electronic data interchange and small organisations: adoption and impact of technology. MIS Quarterly. Vol. 19, No. 4, pp. 465-485.

JARIANGPRASERT, N., TANTIPRAPA, P., CHAIPRASIT, K. and NIMANANDH, K. (2009) The readiness and needs for e-commerce of SMEs in in Chiang Mai province, Thailand. Chulalongkorn Review, Vol. 20, No. 78 (January-March), pp. 77-91.

KENNETH, W., REBECCA, M.N. and EUNICE M.A.A. (2012) Factors affecting adoption of electronic commerce among small and medium enterprises in Kenya: survey of Tour and travel firms in Nairobi. International Journal of Business, Humanities and Technology. Vol.2, No. 4, pp. 76-91.

KHAN, S. (2004) Adoption of electronic commerce in SMEs in Hong Kong. In Chitura, T., Mupemhi, S., Dube, T. and Bolongkikit J. (2008) Barriers to Electronic Commerce Adoption in Small and Medium Enterprises: A Critical Literature Review. Journal of Internet Banking and Commerce. August, Vol. 13, No. 2. [Online] Available from: http://www.arraydev.com/commerce/jibc/

LARSON, T. and ANKOMAH, P. (2004) Evaluating Tourism Web Site Complexity: The Case of International Tourism in the U.S. Services Marketing Quarterly. Vol. 26 No. 2, 23-37. DOI: 10.1300/J396v26n02_02. Retrieved from: http://dx.doi.org/10.1300/J396v26n02_02

LAUDON, K.C. and LAUDON, J.P. (2009) Management Information Systems: Managing the Digital Firm, 11th ed. New Jersey : Prentice Hall.

LAW, R., LEUNG, R. and BUHALIS, D. (2009) Information technology applications in hospitality and tourism: a review of publications from 2005-2007. Journal of Travel \& Tourism Marketing. Vol. 26, No. 5/6, pp. 599-623.

LEECH, N.L., BARRETT, K.C. and MORGAN, G.A. (2005). SPSS for intermediate statistics use and interpretation. Mahwah, New Jersey: Lawrence Erlbaum.

LERTWONGSATIEN, C. and WONGPINUNWATANA, N. (2003) E-commerce adoption in Thailand: An empirical study of small and medium enterprises (SMEs). Journal of Global Information Technology Management. Vol. 6, No. 3, pp. 67-83.

LEUNG, R. and LAW, R. (2005) An analysis of information technology publications in leading hospitality journals. FIU Hospitality Review. Vol. 23, No. 2, 55-65.

LEVY, M. and POWELL, P. (2003) Exploring SMEs internet adoption: towards a contingent model. Electronic Markets. Vol. 13, No. 2, pp. 173-181.

LEVY, M., POWELL, P. and YETTON, P. (2002) The dynamics of SME information systems. Small Business Economics. Vol. 19, No. 4, pp. 341-354.

LI, P. and XIE, W. (2012) A strategic framework for determining e-commerce adoption. Journal of Technology Management in China. Vol. 7, No. 1, pp. 22-35.

LIN, C-S. (2006). Organizational, Technological, and Environmental determinants of electronic commerce adoption in small and medium enterprises in Taiwan, Unpublished Ph.D. Dissertation, Lynn University. ABI/INFORM Complete Database.

LIN, H.F. and LIN, S.M., (2008) Determinants of e-business diffusion: A test of the technology diffusion perspective. Technovation. Vol. 28, pp. 135-145. 
LIP-SAM, T. and HOCK-EAM, L. (2011) Estimating the determinants of B2B e-commerce adoption among small \& medium enterprises. International Journal of Business and Society. Vol. 12, No. 1, pp. 15-30.

MINTZBERG H. (1979) The structuring of organizations. New Jersey : Prentice-Hall.

NGUYEN, T.U.H. (2009) Information technology adoption in SMEs: an integrated framework. International Journal of Entrepreneurial Behaviour and Research. Vol. 15, No. 2, pp. 162-186.

NSO (The National Statistical Office). (2012) E-Commerce Survey. Retrieved from: http://service.nso. go.th/nso/nsopublish/themes/files/electThai Rep55.pdf

NSO (The National Statistical Office) (2013) Tourism Hub" Golden opportunity for Thailand. Retrieved from: http://www.nic.go.th/gsic/uploadfile/Tourism-Hub.pdf

NSO (The National Statistical Office). (2014) The 2013 Survey of E-Commerce Status in Thailand: Executive Summary. Retrieved from: http://web.nso.go.th/en/survey/ict/data_ict/560514 EElectric_13.pdf

OSMEP (Office of Small and Medium Enterprises Promotion). (2012) White Paper on Small and Medium Enterprises of Thailand in 2011 Trends of 2012, part 04: Direction and Measures of SMEs Promotion. Retrieved from: http://www.sme.go.th/SiteCollectionDocuments/ White\%20Paper/2554-new/ Eng_04.pdf

PETERSON, R.A. (1994) A meta-analysis of Cronbach's Coefficient Alpha. The Journal of Consumer Research. Vol. 21, No. 2, pp. 381-391.

PREMKUMAR, G. and RAMAMURTHY, K. (1995) The role of interorganizational and organizational factors on the decision mode for adoption of interorganizational systems. Decision Sciences, Vol. 26, No. 3, pp. 303-336.

RAMDANI, B., CHEVERS, D., and WILLIAMS, D.A. (2013) SMEs' adoption of enterprise applications: A technology-organisation-environment model. Journal of Small Business and Enterprise Development. Vol. 20, No. 4, pp. 735-753.

RAO, S.S., METTS, G. and MONGE, C.A.M. (2003) Electronic commerce development in small and medium sized enterprises: A stage model and its implications. Business Process Management Journal. Vol. 9, No.1, pp. 11-32.

RASHID,M., A., and AL-QIRIM, N., A. (2001) E-commerce technology adoption framework by New Zealand small to medium size enterprises. Research Letters in the Information Mathematical Science. Vol. 2, pp. 63-70.

ROBINSON, J.P., SHAVER, P.R. and WRIGHTSMAN, L.S. (1991) Criteria for Scale Selection and Evaluation. In Measures of Personality and Social Psychological Attitudes, Robinson, JP, Shaver, PR and Wrightsman, LS, eds. San Diego, Calif: Academic Press.

ROGERS, E.M. (1995) Diffusion of Innovations, 4th ed. New York: The Free Press.

ROGERS, E.M. (2003) Diffusion of Innovations, 5th ed. New York: The Free Press. 
TAN, K.S., CHONG, S.C., LIN, B. and EZE, U.C. (2009) Internet-based ICT adoption: evidence from Malaysian SMEs. Industrial Management \& Data Systems. Vol. 109, No. 2, pp. 224-244.

TEO, T.S.H. and PIAN, Y. (2004) A model for web adoption. Information and Management. Vol. 41, No. 4, pp. 457-468.

THONG, J.Y.L. (1999) An integrated model of information systems adoption in small businesses. Journal of Management Information Systems. Vol. 15, No. 4, pp. 187-214.

THONG, J.Y.L. and YAP, C.S. (1995) CEO characteristics, organizational characteristics and information technology adoption in small business. Omega-International Journal of Management Science. Vol. 23, No. 4, pp. 429-442.

THONGTEP, W. (2014, October 29). Thai e-commerce sales continue to rise, boosted by mobile Internet, social media. The Nation, Retrieved from: http://www.nationmultimedia.com/business/ Thai-e-commerce-sales-continue-to-rise-boosted-by--30246457.html

TORNATZKY, L.G. and KLEIN, K.J. (1982) Innovation characteristics and innovation adoption implementation: A meta-analysis of findings. IEEE Transactions on Engineering Management. Vol. 29, No. 1, pp. 28-45.

TORNATZKY, L.G. and FLEISCHER, M. (1990) The processes of technological Innovation. M.A.: Lexington Books, Lexington.

TURBAN, E., KING, D., McKAY, J., MARSHALL, P., LEE, J. and VIEHLAND, D. (2008) Electronic commerce 2008: a managerial perspective. New Jersey: Prentice Hall, Upper Saddle River.

UNCTAD (2004) Electronic Commerce Development Report. Geneva: United Nations.

WANG, S. and CHEUNG, W. (2004) E-Business adoption by travel agencies: Prime candidates for mobile e-business. International Journal of Electronic Commerce. Vol. 8, pp. 43-63.

WANG, Y. and AHMED, P.K. (2009) The moderating effect of the business strategic orientation on eCommerce adoption: Evidence from UK family run SMEs. Journal of Strategic Information Systems. Vol. 18, pp. 16-30.

XU, M., ROHATGI, R. and DUAN, Y. (2007) E-Business Adoption in SMEs: some preliminary findings from electronic components industry. International Journal of E-Business Research. Vol. 3, No. 1, pp. 74-90.

ZHU, K. and KRAEMER, K.L. (2005) Post-adoption variations in usage and value of e-business by organizations: Cross-country evidence from the retail industry. Information Systems Resources, Vol. 16, No. 1, pp. 61-84.

ZHU, K., KRAEMER, K.L. and XU, S. (2003) Electronic business adoption by European firms: a crosscountry assessment of the facilitators and inhibitors. European Journal of Information Systems. Vol.12, No.4, pp. 251-268.

ZHU, K., KRAEMER, K.L. and XU, S. (2006) The process of innovation assimilation by firms in different countries: a technology diffusion perspective on e-business. Management Science. Vol. 52, No. 10, pp. 1557-1576. 
ZHU, K., KRAEMER, K.L., XU, S. and DEDRICK, J. (2004) Information technology payoff in e-business environment: an international perspective on value creation of e-business in the financial services industry. Journal of Management Information Systems. Vol. 21, No. 1, pp. 17-54. 